\title{
Resistência de Plantas aos Herbicidas Inibidores da ACETOLACTATO SINTASE ${ }^{1}$
}

\author{
Plant Resistance to Acetolactate Synthase-Inhibiting Herbicides
}

RIZZARDI, M.A. ${ }^{2}$, VIDAL, R.A. ${ }^{3}$, FLECK, N.G. ${ }^{3}$ e AGOSTINETTO, D. ${ }^{4}$

\begin{abstract}
RESUMO - A resistência de plantas aos herbicidas é conseqüência, na maioria das vezes, de mutação ou da preexistência de genes que conferem resistência à população. No caso dos herbicidas inibidores da acetolactato sintase (ALS) ocorreram casos de resistência tanto em plantas daninhas quanto em culturas. Essa revisão foi realizada com o objetivo de discutir aspectos bioquímicos, genéticos e moleculares da resistência de plantas aos herbicidas inibidores da ALS, sendo destacados também os efeitos na ecofisiologia das plantas daninhas e em mutações que conferem resistência em plantas daninhas e a possibilidade de utilizá-las para o desenvolvimento de culturas resistentes aos inibidores da ALS. Em plantas daninhas, a resistência aos herbicidas inibidores da ALS resulta de uma ou mais mutações no gene que codifica a ALS; quando a herança desse gene é monogênica, ele possui característica dominante a semidominante. As substituições em uma única seqüência nucleotídica ocasionam alteração na ALS, conferindo resistência aos herbicidas inibidores dessa enzima. Embora o biótipo resistente apresente alteração genética e enzimática quando comparado com biótipo suscetível, o comportamento ecofisiológico dos biótipos resistentes e suscetíveis é similar. Essa característica tem implicações muito importantes no estabelecimento das populações resistentes. Já foram desenvolvidos cultivares resistentes para diversas culturas, incluindo arroz e milho, as quais variam no nível de resistência aos diferentes grupos químicos de herbicidas inibidores da ALS.
\end{abstract}

Palavras-chave: plantas daninhas, culturas, mutações, herança da resistência, adaptação ecológica.

\begin{abstract}
Herbicide resistance in plants arises mostly through mutation or pre-existence of genes that confer resistance to the population. When using herbicides inhibitors of the acetolactate synthase (ALS), resistance has occurred in weeds as well as in crops. This literature review was conducted to discuss biochemical, genetic, and molecular aspects of plant resistance to ALS inhibitors, its effects on weed ecophysiology and mutations which confer resistance to weeds, as well as the possibilities to develop resistant crops to ALS inhibitors. In weeds, resistance to ALS-inhibiting herbicides results from one or more mutations in the gene that codifies the ALS, which possesses dominant or semi-dominant characteristics when resistance is codified by one gene. Substitutions on a single nucleotide sequence cause alterations in the ALS, conferring resistance to herbicides inhibitors of this enzyme. Although the resistant biotype presents genetic and enzymatic alteration, when compared to the susceptible biotype, the ecophysiological behaviour of resistant and susceptible biotypes is similar. Resistant cultivars have already been developed in various crops, including rice and corn, which vary in their level of resistance to different chemical groups of ALS-inhibiting herbicides.
\end{abstract}

Key words: weeds, crops, mutations, resistance inheritance, ecological fitness.

Recebido para publicação em 14/9/2001 e na forma revisada em 15/2/2002.

2 Eng.-Agr., Dr., Prof. da Fac. de Agronomia e Medicina Veterinária da Universidade de Passo Fundo - UPF, Caixa Postal 611, 999001-970 Passo Fundo-RS, <rizzardi@upf.tche.br>. ${ }^{3}$ Eng.-Agr., Ph.D., Prof. do Dep. de Plantas de Lavoura da Fac. de Agronomia da Universidade Federal do Rio Grande do Sul - UFRGS, Bolsista do CNPq. ${ }^{4}$ Eng.-Agr., M.S., Aluno do Programa de Pós-Graduação em Fitotecnia da UFRGS.

Planta Daninha, Viçosa-MG, v.20, n.1, p.149-158, 2002 


\section{INTRODUÇÃO}

Resistência de plantas daninhas a herbicidas pode ser definida como a habilidade de um biótipo sobreviver ao tratamento herbicida em doses recomendadas ao qual a população é, normalmente, suscetível. Existem dois modos pelos quais pode surgir resistência em uma população: mutação através da intensidade de seleção recorrente, a qual altera uma população suscetivel para uma população resistente, geração após geração; e preexistência de genes na população (Ohmes \& Kendig, 1999). É importante destacar que o herbicida é o agente selecionador do biótipo resistente através da pressão de seleção, não sendo, portanto, o agente mutagênico responsável pelo aparecimento dos genes mutantes que surgem na população por variabilidade genética natural.

A acetolactato sintase (ALS) é a primeira enzima na via metabólica de biossíntese dos aminoácidos alifáticos de cadeia ramificada leucina (Leu), valina (Val) e isoleucina (Ile). Imidazolinonas (IMI), sulfoniluréias (SUL), triazolopirimidina sulfonanilidas (TRS) e pirimidil-oxi-tiobenzoato (POT) são os principais grupos químicos de herbicidas que inibem essa enzima (Leite et al., 1998).

A seleção de biótipos de plantas resistentes aos herbicidas inibidores da ALS é um fenômeno emergente na maioria das regiões produtoras de soja no Brasil, resultante do uso repetitivo de herbicidas com esse mecanismo de ação. A partir da identificação do primeiro caso de resistência de plantas a herbicidas inibidores da ALS em Lactuca serriola, em 1987, já foram detectados casos similares em 69 espécies de plantas daninhas em várias regiões agrícolas do mundo (HRAC, 2001); destes, 48 ocorreram em dicotiledôneas e 21 em monocotiledôneas. No Brasil, foram relatados casos de resistência aos herbicidas inibidores da ALS em Euphorbia heterophylla (Gazziero et al., 1998; Vidal \& Merotto Jr., 1999; Vargas et al., 1999), em Bidens pilosa (Ponchio, 1997) e em Sagitaria montevidensis (Noldin et al., 1999).

No entanto, considerando-se a limitação da seletividade dos herbicidas como único obstáculo para o uso de um composto em várias culturas, podem ser testados diferentes métodos para melhorar essa propriedade. Nesse contexto, a resistência de plantas cultivadas a herbicidas constitui-se em mecanismo para introduzir seletividade adicional às culturas cuja limitação de herbicidas recomendados exista.

Nesta revisão serão discutidos aspectos bioquímicos, genéticos e moleculares da resistência de plantas aos herbicidas inibidores da ALS, com ênfase em efeitos na ecofisiologia das plantas daninhas e em mutações que conferem resistência em plantas daninhas e na possibilidade de utilizá-las para o desenvolvimento de culturas resistentes aos herbicidas inibidores da ALS.

\section{RESISTÊNCIA DE PLANTAS DANINHAS AOS HERBICIDAS INIBIDORES DA ALS}

A probabilidade de infestação de uma área com um biótipo resistente de uma população de plantas daninhas depende de vários fatores, como adaptabilidade ecológica e prolificidade do indivíduo, longevidade e dormência das sementes da espécie ou do biótipo sob seleção, freqüência de utilização de herbicidas com mesmo mecanismo de ação e sua persistência no solo, eficácia do herbicida e métodos adicionais empregados no controle da planta daninha (Jasieniuk et al., 1996; Dekker, 1997; Vidal \& Fleck, 1997; Trezzi \& Vidal, 2000). Resultados de simulações de predição da seleção de biótipos resistentes indicam que o principal fator que determina a ocorrência de resistência de plantas a herbicidas numa área específica é a freqüência inicial do gene que codifica a característica de resistência, ou seja, em situações de alta infestação de certa espécie daninha, há grande probabilidade de se encontrar um mutante resistente ao(s) herbicida(s) (Vidal \& Fleck, 1997).

As espécies de plantas tolerantes aos herbicidas IMI e SUL geralmente apresentam aumento no metabolismo do herbicida ou metabolismo diferencial em relação às suscetiveis (Vargas et al., 1999). Todos os biótipos de plantas resistentes aos inibidores da ALS, nos quais o mecanismo de resistência foi determinado, são resistentes devido à presença de ALS, cujo sítio de ação do herbicida foi alterado e, assim, torna-se insensível aos herbicidas (Boutsalis et al., 1999). Os biótipos resistentes 
freqüentemente apresentam resistência cruzada aos herbicidas pertencentes ao mesmo grupo químico com o qual o biótipo foi selecionado, mas possuem padrões diversos de resistência cruzada a outros grupos químicos de herbicidas inibidores da ALS (Gazziero et al., 1998; Manley et al., 1998; Vidal \& Merotto Jr., 1999; Vargas et al., 1999).

Ao trabalharem com Euphorbia heterophylla, Gazziero et al. (1998) constataram que o biótipo resistente apresentou níveis variáveis de resistência cruzada aos herbicidas inibidores da ALS, pertencentes aos grupos IMI e SUL, com valores médios de $\mathrm{GR}_{50}$ (dose herbicida necessária para reduzir 50\% da biomassa das plantas tratadas com herbicida, em comparação com as não-tratadas) entre 6,85 e 11,90, respectivamente. Também para essa espécie, Vargas et al. (1999) constataram que o biótipo resistente possuía resistência cruzada aos herbicidas IMI (imazaquin, imazethapyr e imazamox) e SUL (nicosulfuron). Comportamento semelhante foi constatado para Amaranthus hybridus, em área com aplicação repetitiva de imazaquin (Manley et al., 1998). Outros trabalhos relatam resistência a imazaquin e nenhum nível de resistência a chlorimuron (SUL) ou a chloransulam-methyl (TRS) em biótipos de $A$. hybridus (Manley et al., 1999; Poston et al., 2000). Poston et al. (2000) observaram que as populações resistentes foram mais tolerantes a chlorimuron do que a cloransulam-methyl.

Os resultados obtidos para E. heterophylla e A. hybridus reforçam as constatações de Wright et al. (1998), de que a resistência cruzada para herbicidas inibidores da ALS pertencentes a diferentes grupos químicos é resultado de uma única mutação ou combinação de duas mutações separadas no gene que codifica a ALS, onde cada mutação resulta na resistência a um grupo de herbicidas inibidores da enzima, pertencente ao mesmo grupo químico.

\section{Mutações identificadas em plantas daninhas resistentes}

Mutações espontâneas, nos genes que codificam um determinado aminoácido, resultam em resistência à ALS; a pressão de seleção aumenta a freqüência do biótipo resistente. Assim, uma única substituição na base nucleotídica confere resistência aos inibidores da ALS (Wetzel et al., 1999). Em Kochia scoparia, o ponto de mutação que codifica mudanças na prolina (Pro 173) foi associado com a seleção de biótipos resistentes a SUL (Guttieri et al., 1992). Em Amaranthus rudis, o aminoácido triptofano (Trp), mutado para Leu por uma única substituição de guanina para timina na posição 569 no gene, conferiu resistência aos inibidores da ALS (Foes et al., 1998).

As mudanças que foram obtidas na seqüência de aminoácidos foram identificadas dentro de uma a cinco regiões altamente conservadas (dominios) do gene ALS (Wright et al., 1998; Boutsalis et al., 1999). Esses domínios variam em tamanho de 12 a 57 pares de bases e são referidos como domínios A a E. Mudanças nos aminoácidos de todos os cinco domínios foram observadas em biótipos selecionados em laboratório, mas somente quatro foram constatados em isolados oriundos do campo (Boutsalis et al., 1999; Lee \& Owen, 2000).

No domínio A, todas as possiveis substituições que resultam de uma única mudança nucleotídica (serina, leucina, glutamina, alanina, treonina, arginina e histidina) estão associadas com resistência no campo, sendo esse o caso da substituição ocorrida para Kochia scoparia (Guttieri et al., 1992); no entanto, no domínio $\mathrm{B}$, das sete mudanças nucleotídicas possíveis, foi constatada, a partir de plantas oriundas do campo, somente a substituição de Trp por Leu. Essa substituição foi relatada para biótipos resistentes de Xanthium strumarium (Trp555 para Leu) (Bernasconi et al., 1995) e de Amaranthus sp. (Trp569 para Leu) (Woodworth et al., 1996). No caso do domínio C, somente foram observadas substituições para isolados de Xanthium (Bernasconi et al., 1995). Um terceiro biótipo de $X$. strumarium, com substituição no domínio D, conferiu resistência cruzada a todos os inibidores da ALS, semelhantemente à substituição verificada no domínio B (Boutsalis et al., 1999).

As descobertas relatadas por Dewaele et al. (1997), Wright et al. (1998) e Boutsalis et al. (1999) indicam que o padrão de resistência não é determinado pelo local da mutação, mas, principalmente, pela substituição do aminoácido específico no respectivo local.

O conhecimento das diferentes substituições que ocorrem nas seqüências de aminoácidos 
pode explicar o aparecimento ou não de resistência cruzada aos herbicidas inibidores da ALS. Em Brassica napus, um único ponto de mutação resultante da substituição do Trp por Leu na posição 557 no gene AHAS3R resultou em resistência a SUL e IMI (Dewaele et al., 1997). Uma mutação idêntica afetou mutantes SurB e S4Hra de tabaco, o que sugere localização no local de ligação do herbicida na ALS. Entretanto, a falta de resistência cruzada em alguns mutantes reforça a presença de domínios separados no mesmo local de ligação, controlando a natureza e o grau de inibição. Uma mutação dentro desse local afeta um ou mais domínios, conferindo resistência isolada ou cruzada. Na cultura da chicória, as diferenças nos níveis de resistência a chlorsulfuron e imazamethabenz indicam a existência de um único local com sobreposição nos domínios de ligação (Dewaele et al., 1997). O seqüenciamento dos genes que codificam para formas de ALS sensiveis e resistentes pode esclarecer esses pontos.

\section{Herança da resistência}

O conhecimento da herança genética dos genes que conferem resistência é de grande importância para estudar e prever sua evolução (Vargas et al., 2001). Em Sisymbrium orientale, as razões de segregação observadas para cada grupo químico de herbicida não diferiram significativamente da razão predita de segregação 3:1. Essas descobertas indicam que, para essa espécie, a resistência é controlada por um único gene que exibe dominância incompleta (Boutsalis et al., 1999). Para Euphorbia heterophylla, a resistência é controlada por um alelo nuclear dominante (Vargas et al., 2001).

Em trabalho conduzido por Ohmes \& Kendig (1999), a geração $F_{2}$ de biótipos suscetíveis de Xanthium strumarium, submetido à polinização cruzada com biótipos resistentes a herbicidas inibidores da ALS, recebeu tratamento com mistura em tanque de imazaquin + chlorimuron. Nesse caso, foram observados três comportamentos distintos (plantas resistentes, intermediárias e suscetíveis), indicando que a resistência cruzada é característica variável de dominante a semidominante.

Vargas et al. (2001) não obtiveram diferenças no grau de resistência entre os biótipos homozigotos resistentes e heterozigotos de $E$. heterophylla quando submetidos a aplicações de até $1.600 \mathrm{~g} \mathrm{ha}^{-1}$ de imazethapyr, o que indica tratar-se de um caso de dominância completa desse gene. Resultado semelhante foi constatado por Lee \& Owen (2000). Adicionalmente, a comparação da atividade da enzima de plantas de chicória homozigotas e heterozigotas resultou em uma curva de padrão bifásico, indicando a presença de uma ALS resistente junto com uma forma sensivel (Boutsalis et al., 1999).

\section{Propriedades da ALS}

As bases bioquímicas e moleculares da resistência estão caracterizadas para alguns biótipos de plantas daninhas. Por exemplo, a resistência de Euphorbia heterophylla ao herbicida imazethapyr se deve à modificação na ALS e não a diferenças na absorção, translocação ou metabolização do herbicida nos biótipos resistentes e suscetiveis (Vargas et al., 1999).

Eberlein et al. (1997) verificaram que tanto a localização do ponto de mutação no gene quanto a substituição específica do aminoácido na enzima afetam a estrutura e a função da ALS e, assim, reduzem sua atividade. Nesse trabalho, os autores obtiveram 57\% de diferenças na atividade da enzima entre biótipos resistentes e suscetiveis de Lactuca serriola. No entanto, a comparação da atividade relativa da ALS não revelou diferenças significativas entre biótipos resistentes e suscetíveis de Xanthium strumarium (Lee \& Owen, 2000).

Uma das formas de avaliar as propriedades bioquímicas de uma enzima é verificando a sua afinidade pelo substrato. A habilidade pelo substrato piruvato, medido como Km (concentração de substrato que fornece velocidade inicial igual à metade da velocidade máxima da reação), foi similar entre biótipos resistentes e suscetiveis nas espécies Brassica tournefortii e Sisymbrium orientale (Boutsalis et al., 1999). Entretanto, na espécie $S$. orientale, a velocidade máxima da reação no biótipo resistente foi maior do que no suscetível, sugerindo que a superexpressão da ALS pode contribuir para a resistência. No entanto, experimentos utilizando a técnica de hibridação Northern blot, conduzidos com plantas sensiveis e resistentes, falharam em mostrar diferenças substanciais 
entre duas linhagens de chicória, indicando que a tolerância não era devida à superexpressão da enzima-alvo (Dewaele et al., 1997). Em Euphorbia heterophylla, não houve mudança significativa na atividade da ALS pelo substrato, porém a eficiência da enzima foi alterada, uma vez que houve aumento de $75 \%$ no valor da velocidade máxima (Vargas et al., 1999). Com esse trabalho, os autores constataram que a resistência dos biótipos aos herbicidas inibidores da ALS é atribuída à insensibilidade da enzima e não à superexpressão da enzima-alvo.

Outra especulação a ser comprovada refere-se ao fato de a atividade da ALS também ser modulada pelos produtos finais da rota, ou seja, os aminoácidos Ile, Leu e Val, os quais exercem inibição alostérica da enzima por realimentação, controlando assim a velocidade de sua própria síntese (Coruzzi \& Last, 2000). Herbicidas SUL e IMI podem se ligar no mesmo local ou em locais diferentes da enzima, pois são não-competitivos com o substrato. A ocorrência de mutação que iniba a afinidade do herbicida pode, eventualmente, também afetar a afinidade do ligante natural; nesse caso, os dois locais podem influenciar um ao outro, conduzindo a alterações nas propriedades de realimentação, ou podem não interagir e tornaremse independentes (Dewaele et al., 1997). As informações disponiveis na literatura sobre essa teoria ainda são inconclusivas.

As ligações dos herbicidas e dos aminoácidos Val ou Leu podem ser mutuamente exclusivas, indicando que o correspondente local de ligação pode se sobrepor. No caso de chicória resistente, o efeito inibitório de Leu, comparado ao de Val, foi mais reduzido, o que leva à hipótese de que seus domínios de ligação não são exatamente sobrepostos (Dewaele et al., 1999). Como o domínio de ligação Leu inclui um local de ligação com regiões aniônicas e/ou hidrofóbicas do herbicida, herbicidas e Leu podem ligar-se no mesmo local ou a dois locais completamente sobrepostos, enquanto Val liga-se a locais diferentes. Uma hipótese alternativa de que aminoácidos ligam-se no mesmo local estaria associada ao fato de que mutação conferindo resistência aos herbicidas pode modificar também a estrutura quaternária da enzima, reduzindo assim a acessibilidade de ambos os aminoácidos, mais particularmente a Leu, a qual possui um grupo hidrofóbico adicional.
A disponibilização de mais relatos moleculares da substituição de nucleotídeos que codificam a resistência permitirá que possam ser feitas correlações entre substituições específicas e os perfis de resistência que elas codificam em níveis de enzima e de planta.

\section{Efeitos na ecofisiologia das plantas daninhas}

A capacidade de sobrevivência e reprodução de um biótipo em uma população determina a sua adaptabilidade ecológica, a qual depende de características biológicas, como taxas de germinação, crescimento e produção de sementes (Christoffoleti, 2001). A adaptabilidade ecológica entre biótipos resistentes e suscetíveis tem sido comparada através da análise de crescimento de plantas daninhas em condições competitivas entre biótipos, em plantas isoladas e também em condições de competição interespecífica entre plantas daninhas e cultivadas (Trezzi \& Vidal, 2000).

A hipótese de que biótipos resistentes a herbicidas possuem menor habilidade competitiva do que biótipos suscetíveis surgiu de observação em biótipos resistentes aos herbicidas pertencentes ao grupo químico das triazinas, os quais apresentam menor taxa de crescimento e capacidade reprodutiva em relação aos biótipos suscetiveis, na ausência do herbicida (Jasieniuk et al., 1996). Para os biótipos de plantas daninhas resistentes às triazinas, a mutação que resulta em única alteração no fotossistema II da planta se reflete em efeitos pleiotrópicos no biótipo resistente, alterando sua eficácia fotossintética (Dekker, 1997). No caso dos herbicidas inibidores da ALS, a inibição dessa enzima não influencia o aparato fotossintético, não ocasionando, desse modo, desempenho ecológico inferior em biótipos resistentes. Em condições não-competitivas, não foram constatadas diferenças na massa da parte aérea de Kochia scoparia entre biótipos resistentes e suscetiveis aos inibidores de ALS (Thompson et al., 1994; Christoffoleti et al., 1997). Resultados semelhantes foram observados em Euphorbia heterophylla, não sendo constatadas diferenças entre os biótipos resistentes e suscetiveis aos herbicidas inibidores da ALS para as variáveis área foliar, massa seca total, taxa de crescimento relativo, 
taxa assimilatória líquida e razão de área foliar (Trezzi \& Vidal, 2000; Vidal \& Trezzi, 2000; Brighenti et al., 2001). Para Bidens pilosa, Christoffoleti (2001) relatou não haver diferenças nos padrões de crescimento entre os biótipos resistentes e suscetiveis aos inibidores da ALS sob condições não-competitivas. Pelos resultados apresentados, constata-se que a modificação causada na ALS, e que confere resistência, não está correlacionada ao decréscimo na produtividade da planta. Portanto, biótipos resistentes não levariam vantagens ou desvantagens na competição com biótipos suscetiveis aos herbicidas inibidores de ALS, quando cultivados na ausência da aplicação desses herbicidas (Vidal \& Trezzi, 2000).

O conhecimento da ecofisiologia dos biótipos resistentes aos herbicidas inibidores da ALS é importante para que possam ser recomendadas medidas de manejo à resistência. Nesse sentido, Christoffoleti (2001) salienta que, na ausência de diferenças em habilidade competitiva entre biótipos resistentes e suscetíveis, devam ser adotadas estratégias preventivas à seleção de biótipos resistentes, pois, uma vez selecionado um biótipo resistente, a população não retorna naturalmente à freqüência original de suscetibilidade. Associado a isso, e para espécies de plantas daninhas que possuam polinização cruzada, poderá ocorrer cruzamento entre os biótipos resistentes e suscetiveis, aumentando rapidamente a freqüência do biótipo resistente, como foi constatado em Helianthus annuus por Marshall et al. (2001).

Uma vez estabelecida uma população de plantas daninhas resistente aos herbicidas inibidores da ALS, devem-se buscar alternativas para reduzir o problema. Entre as estratégias de manejo incluem-se rotação ou mistura de herbicidas com diferentes mecanismos de ação (Marshall et al., 2001; Monquero \& Christoffoleti, 2001). No entanto, o sucesso no manejo da resistência com uso de herbicidas alternativos constitui-se em opção de sucesso a curto prazo, uma vez que, se forem utilizados intensivamente, há risco de também se desenvolver resistência para esses herbicidas alternativos (Monquero \& Christoffoleti, 2001).

É importante que se busquem outras estratégias de controle das populações resistentes de plantas daninhas. Desse modo, um fatorchave no manejo dessas populações, em nível de campo, é o banco de sementes de plantas daninhas presente no solo. Diferenças em características como viabilidade, dormência e germinação das sementes influenciam diretamente o manejo de áreas infestadas com populações de plantas daninhas resistentes e também a persistência dessas populações no campo (Kremer \& Lotz, 1998). Nesse sentido, Eberlein et al. (1999) hipotetizaram que a redução na inibição por realimentação da ALS de Lactuca sativa pelos aminoácidos Val, Leu e Ile resulta em maior concentração desses aminoácidos em sementes de biótipos resistentes do que em suscetiveis. Essas diferenças no conteúdo de aminoácidos possibilitariam germinação mais rápida de biótipos resistentes, permitindo que ocupem mais rapidamente o espaço disponivel do que os biótipos suscetíveis. Além disso, foi observado pelos autores que as sementes do biótipo resistente apresentavam menor dormência e germinação em maior amplitude de temperatura, permitindo assim que seu estabelecimento ocorresse sob ampla variação ambiental.

A diminuição do banco de sementes, seja pela redução da dormência ou pelo estímulo da germinação, pode auxiliar no manejo das populações de plantas daninhas resistentes aos herbicidas inibidores da ALS. O estímulo da germinação de plantas daninhas por herbicidas e o subseqüente desenvolvimento de plântulas são fenômenos raros; entretanto, Chandran et al. (1999) obtiveram aumento de $37 \%$ na germinação de Bidens pilosa após o tratamento do solo com o herbicida thiazopyr.

\section{RESISTÊNCIA DE CULTURAS AOS HERBICI- DAS INIBIDORES DA ALS}

O aumento da disponibilidade de herbicidas recomendados para determinada cultura pode ser obtido através da incorporação de novos mecanismos de seletividade em culturas normalmente sensíveis a herbicidas já existentes no mercado e recomendados para outras culturas (Merotto Jr. et al., 2000). A incorporação de resistência em culturas suscetiveis possibilita ampliação das alternativas de controle para aquelas espécies com reduzido número de herbicidas seletivos, uso de herbicidas mais eficientes e seguros, ampliação no 
espectro de controle de plantas daninhas, inclusive para as da mesma espécie da cultura, planejamento de sistemas de rotação de culturas sem a preocupação com resíduos para a cultura subseqüente e auxílio no manejo de áreas com plantas daninhas resistentes.

Resistência aos inibidores da ALS foi obtida em algumas espécies de plantas, como Nicotiana tabacum, Arabidopsis thaliana, Glycine max, Linum usitatissimum, Datura innoxia, Lotus corniculatus, Brassica napus, Daucus carota (Dewaele et al., 1997), Beta vulgaris (Wright et al., 1998) e Zea mays (Wright \& Penner, 1998c). Na obtenção de culturas resistentes aos herbicidas, três estratégias podem ser utilizadas: transferência de genes que codificam enzima insensivel ao herbicida, superprodução da enzima sensível e metabolização do herbicida (Merotto Jr. et al., 2000). No caso dos inibidores da ALS, utiliza-se, principalmente, o primeiro mecanismo, embora haja relatos da obtenção de mutantes em laboratório com aumento da expressão gênica em plantas de cenoura, através da superprodução da ALS (Caretto et al., 1994).

\section{Métodos de obtenção de culturas resistentes}

A seleção de plantas resistentes em uma cultura pode ser acelerada usando-se métodos de biotecnologia, como seleção de plantas inteiras, seleção em meio de cultura, hibridações, mutagênese e transferência de genes (Wright \& Penner, 1998b; Wright \& Penner, 1998c).

O uso de células, em vez da seleção da planta toda, permite que a mutação ocorra em meses e a transferência dos genes de resistência também necessite de um período curto. Como as células vegetais são totipotentes, uma planta pode ser regenerada a partir de uma única célula viável. Células de plantas que expressam um gene de resistência a determinado herbicida podem ser selecionadas e identificadas eficientemente sob condições em que a dose letal do herbicida correspondente iniba o crescimento de células inalteradas.

Em princípio, todos os tipos de plantas in vitro são acessiveis para a seleção de mutantes. Contudo, por questões práticas, calos e suspensões de células regeneradas de genótipos de plantas são as fontes mais apropriadas
(Ferreira et al., 1998). Exemplares de mutantes oriundos da seleção in vitro foram obtidos para herbicidas SUL em tabaco, arroz e milho (Sprague et al., 1999), para IMI em milho (Wright \& Penner, 1998c) e para IMI e SUL em beterraba (Wright \& Penner, 1998b).

Atualmente, para a maioria das culturas, estão sendo desenvolvidos métodos para transformação genética de plantas e introdução de genes isolados (Brasileiro \& Dusi, 1999; Polowick et al., 2000). Para espécies dicotiledôneas, o vetor utilizado é Agrobacterium tumefasciens. Para monocotiledôneas, diferentes métodos foram desenvolvidos, como a biobalística e o cultivo de protoplastos. Utilizando-se essas técnicas, genes csrl foram isolados de mutantes de Arabidopsis resistentes a SUL e IMI e transferidos para tabaco e arroz (Brasileiro \& Dusi, 1999). Assim, as plantas transgênicas contendo o gene mutado csrl produzem uma ALS alterada, não reconhecida pelos herbicidas SUL e IMI, tornando, conseqüentemente, a planta resistente a esses produtos.

\section{Genes e mutações que conferem resistência}

Em estudos de laboratório, foram identificadas algumas mutações no gene que codifica ALS e que conferem resistência aos herbicidas inibidores desta enzima. Em beterraba, por exemplo, resistência a SUL foi devida à ALS com reduzida sensibilidade, herdada como alelo semidominante (sur); já a resistência a IMI (alelo sir13) e a resistência cruzada a IMI e SUL (alelo 93R30B) foram herdadas como alelo semidominante monogênico (Wright \& Penner, 1998a). No caso de milho resistente a IMI, os híbridos são divididos em grupos (IT, IR e IMR) (Sprague et al., 1999). Híbridos IT são heterozigotos para resistência a IMIs (alelo mut2) e são resistentes somente a IMIs. Os híbridos IR (alelo $X A-17$ ) e IMR são homozigotos, e os IRs são resistentes a diferentes grupos de herbicidas inibidores da ALS.

Dois ou mais domínios alterados, em um único indivíduo, podem não somente resultar em biótipos $\mathrm{R}$ com perfis mais amplos de resistência, mas também em maior resistência total, devido ao sinergismo entre os domínios (Boutsalis et al., 1999). Essa descoberta, aliada ao fato de que a característica semidominante 
da resistência expressa maior nível de resistência em condições homozigotas do que heterozigotas, possibilita, através do melhoramento tradicional, combinar as classes de resistência específica (como os alelos sur e sir13 de beterraba) (Boutsalis et al., 1999). No entanto, Wright \& Penner (1998a) salientam que em culturas como beterraba, com somente um locus ALS e um alelo expresso em homozigose, esse procedimento não é possível. Para esses casos, a amplificação do espectro de resistência pode ser facilitada pelo uso de alelos resistentes tanto a SUL quanto a IMI, como ocorre com o 93R30B em beterraba (Wright \& Penner, 1998b), ou o alelo XA-17 em milho (Sprague et al., 1999).

A resistência de plantas aos herbicidas inibidores da ALS pode, de um lado, ser um aspecto positivo quando associada à cultura, pois o seu uso aumenta a flexibilidade no manejo de plantas daninhas-problema. No entanto, é negativo quando ocorre em plantas daninhas. Nestas, a resistência resulta de uma única mutação ou da combinação de duas mutações no gene que codifica a ALS e possui característica dominante a semidominante. As substituições em uma seqüência nucleotídica em determinadas regiões da enzima ocasionam alteração na ALS, conferindo resistência aos herbicidas inibidores dessa enzima. Assim, é importante o conhecimento das implicações da resistência na ecofisiologia, bioquímica e dinâmica populacional da planta daninha resistente para que medidas de prevenção e manejo sejam adotadas de forma racional na agricultura.

\section{LITERATURA CITADA}

BERNASCONI, P. et al. A naturally-occurring point mutation confers broad range tolerance to herbicides that target acetolactate synthase. J. Biol. Chem., v. 270, n. 8, p. 17381-17385, 1995.

BOUTSALIS, P.; KAROTAM, J.; POWLES, S. Molecular basis of resistance to acetolactate synthase-inhibiting herbicides in Sisymbrium orientale and Brassica tournefortii. Pest. Sci., v. 55, n. 5, p. 507-516, 1999.

BRASILEIRO, A. C. M.; DUSI, D. M. A. Transformação genética de plantas. In: TORRES, A. C.; CALDAS, L. S.; BUSO, J. M.. Cultura de tecidos e transformação genética de plantas. Brasília: SPI-EMBRAPA, 1999. v.2. p. 679-735.

Planta Daninha, Viçosa-MG, v.20, n.1, p.149-158, 2002
BRIGHENTI, A. M. et al. Análise de crescimento de biótipos de amendoim-bravo (Euphorbia heterophylla) resistente e suscetível aos herbicidas inibidores da ALS. Planta Daninha, v. 19, n. 1, p. 51-59, 2001.

CARETTO, S.; GIARDINA, M. C.; NICOLODI, C. Chlorsulfuron resistance in Daucus carota cell lines and plants: involvement of gene amplification. Theor. Appl. Genetics, v. 88, n. 4, p. 520-524, 1994.

CHANDRAN, R. S.; SINGH, M.; SALIHU, S. Thiazopyr stimulates hairy beggarticks (Bidens pilosa) germination. Weed Technol., v. 13, n. 3, p. 576-580, 1999.

CHRISTOFFOLETI, P. J. Análise comparativa do crescimento de biótipos de picão-preto (Bidens pilosa) resistente e suscetível aos herbicidas inibidores da ALS. Planta Daninha, v. 19, n. 1, p. 75-83, 2001.

CHRISTOFFOLETI, P. J.; WESTRA, P.; MOORE, F. Growth analysis of sulfonylurea-resistant and susceptible kochia (Kochia scoparia). Weed Sci., v. 45, n. 5, p. 691695, 1997.

CORUZZI, G.; LAST, R. Amino acids. In: BUCHANAN, B. B.; GRUISSEM, W.; JONES, R.L. Biochemistry \& molecular biology of plants. Maryland: American Society of Plant Physiologists, 2000. p. 358-410.

DEKKER, J. Weed diversity and weed management. Weed Sci., v. 45, n. 3, p. 357-363, 1997.

DEWAELE, E. et al. Biochemical characterization of chlorsulfuron resistance in Cichorium intybus L. var. Witloof. J. Plant Physiol., v. 151, n. 1, p. 109-114, 1997.

EBERLEIN, C. V. et al. Altered acetolactate synthase activity in ALS-inhibitor resistant prickly lettuce (Lactuca serriola). Weed Sci., v. 45, n. 2, p. 212-217, 1997.

EBERLEIN, C. V. et al. Physiological consequences of mutation for ALS-inhibitor resistance. Weed Sci., v. 47, n. 4, p. 383-392, 1999.

FERREIRA, M. E.; CALDAS, L. S.; PEREIRA, E. A. Aplicações da cultura de tecidos no melhoramento genético de plantas. In: TORRES, A. C.; CALDAS, L. S.; BUSO, J. M. Cultura de tecidos e transformação genética de plantas. Brasília: SPI-EMBRAPA, 1998. v.1. p. 21-43.

FOES, M. J.; LIU, L.; TRANEL, P. J. A biotype of common waterhemp (Amaranthus rudis) resistant to triazine and ALS herbicides. Weed Sci., v. 46, n. 5, p. 514-520, 1998.

GAZZIERO, D.L.P. et al. Resistência de amendoim-bravo aos herbicidas inibidores da enzima ALS. Planta Daninha, v. 16, n. 2, p. 117-125, 1998. 
GUTTIERI, M.J. et al. DNA sequence variation in domain A of the acetolactate synthase genes of herbicide resistant and susceptible weed biotypes. Weed Sci., v. 40, n. 6, p. 670-677, 1992.

\section{HERBICIDE RESISTANCE ACTION COMMITTEE -} HRAC. Herbicide resistant weeds summary table. (Web: http://weedresearch.com/summary/MOASumary.asp. 29/08/ 2001)

JASIENIUK, M.; BRULÉ-BABEL, A. L.; MORRISON, I. $\mathrm{N}$. The evolution and genetics of herbicide resistance in weeds. Weed Sci., v. 44, n. 2, p. 176-193, 1996.

KREMER, E.; LOTZ, L. A. P. Germination and emergence characteristics of triazine-susceptible and triazine-resistant biotypes of Solanum nigrum. J. Appl. Ecol., v. 35, n. 2, p. $302-310,1998$.

LEE, J. M.; OWEN, M. D. K. Comparison of acetolactate synthase enzyme inhibition among resistant and susceptible Xanthium strumarium biotypes. Weed Sci., v. 48, n. 3, p. 286-290, 2000.

LEITE, C. R. F.; ALMEIDA, J. C. V.; PRETE, C. E. Aspectos fisiológicos, bioquímicos e agronômicos dos herbicidas inibidores da enzima ALS (AHAS). Londrina: Edição do autor, 1998. 68 p.

MANLEY, B. S.; WILSON, H. P.; HINES, T. E. Characterization of imidazolinone resistant smooth pigweed (Amaranthus hybridus). Weed Technol., v. 14, n. 3, p. 575584, 1998.

MANLEY, B. S. et al. Imidazolinone resistance in smooth pigweed (Amaranthus hybridus) is due to an altered acetolactate synthase. Weed Technol., v. 13, n. 4, p. 697$705,1999$.

MARSHALL, M. W.; AL-KHATIB, K.; LOUGHIN, T. Gene flow, growth, and competitiveness of imazethapyr-resistant common sunflower. Weed Sci., v. 49, n. 1, p. 14-21, 2001.

MEROTTO Jr., A.; VIDAL, R. A.; FLECK, N. G. Tolerância da cultivar de soja Coodetec 201 aos herbicidas inibidores de ALS. Planta Daninha, v. 18, n. 1, p. 93-102, 2000.

MONQUERO, P. A.; CHRISTOFFOLETI, P. J. Manejo de populações de plantas daninhas resistentes aos herbicidas inibidores da acetolactato sintase. Planta Daninha, v. 19, n. 1, p. 67-74, 2001.

NOLDIN, J. A.; EBERHARDT, D. S.; KNOBLAUCH, R. Resistência de Sagitaria montevidensis a herbicidas: primeiras evidências. In: CONGRESSO BRASILEIRO DA ARROZ IRRIGADO, 1; REUNIÃO DA CULTURA DO ARROZ IRRIGADO, 23, 1999, Pelotas. Anais... Pelotas: Embrapa Clima Temperado, 1999. p. 566-569.
OHMES, G. A.; KENDIG, J. A. Inheritance of an ALScross-resistant common cocklebur (Xanthium strumarium) biotype. Weed Technol., v. 13, n. 1, p. 100-103, 1999.

POLOWICK, P. I.; QUANDT, I.; MAHON, I. D. The ability of pea transformation technology to transfer genes into peas adapted to western Canadian growing conditions. Plant Sci., v. 153, n. 2, p. 161-170, 2000.

PONCHIO, J. A. R. Resistência de biótipos de Bidens pilosa L. a herbicidas inibidores da enzima ALS/AHAS. Piracicaba: Escola Superior de Agricultura "Luiz de Queiroz", 1997. 120 p. Tese (Doutorado em Fitotecnia) Escola Superior de Agricultura "Luiz de Queiroz”, 1997.

POSTON, D. H.; WILSON, H. P.; HINES, T. E. Imidazolinone resistance in several Amaranthus hybridus populations. Weed Sci., v. 48, n. 4, p. 508-513, 2000.

SPRAGUE, C. L.; FRASIER, A. L.; PENNER, D. Identifying acetolactate synthase inhibitors for potential control of quackgrass (Elytrigia repens) and Canada thistle (Cirsium arvense) in corn (Zea mays). Weed Technol., v. 13, n. 1, p. 54-58, 1999.

THOMPSON, C. R.; THILL, D. C.; SHAFII, B. Growth and competitiveness of sulfonylurea-resistant and susceptible kochia (Kochia scoparia). Weed Sci., v. 42, n. 2, p. 172-179, 1994.

TREZZI, M. M.; VIDAL, R. A. Crescimento estival de três biótipos de leiteira resistentes e um suscetível aos herbicidas inibidores da acetolactato sintase. R. Bras. Herb., v. 1, n. 3, p. 255-260, 2000.

VARGAS, L. et al. Resistência de plantas daninhas a herbicidas. Viçosa, MG: Jard, 1999. 131 p.

VARGAS, L.; BORÉM, A.; SILVA, A. A. Herança da resistência aos herbicidas inibidores da ALS em biótipos da planta daninha Euphorbia heterophylla. Planta Daninha, v. 19, n. 3, p. 331-336, 2001.

VIDAL, R. A.; FLECK, N. G. Análise de risco da ocorrência de biótipos de plantas daninhas resistentes aos herbicidas. Planta Daninha, v. 15, n. 12, p. 152-161, 1997.

VIDAL, R. A.; MEROTTO Jr., A. Resistência de amendoim-bravo aos herbicidas inibidores da enzima acetolactato sintase. Planta Daninha, v. 17, n. 3, p. 367373, 1999.

VIDAL, R. A.; TREZZI, M. M. Análise de crescimento de biótipos de leiteira (Euphorbia heterophylla) resistentes e suscetível aos herbicidas inibidores da ALS. Planta Daninha, v. 18, n. 3, p. 427-433, 2000.

Planta Daninha, Viçosa-MG, v.20, n.1, p.149-158, 2002 
WETZEL, D. K. et al. Transfer of herbicide resistance traits from Amaranthus palmeri to Amaranthus rudis. Weed Sci., v. 47, n. 5, p. 538-543, 1999.

WOODWORTH, A. R.; ROSEN, B. A.; BERNASCONI, P. Broad range resistance to herbicides targeting acetolactate synthase (ALS) in a field isolate of Amaranthus sp. is conferred by a TRP to LEU mutation in the ALS gene. Plant Physiol., v. 111, n. 4, p. 1353-1357, 1996.

WRIGHT, T. R. et al. Biochemical mechanism and molecular basis for ALS-inhibiting herbicide resistance in sugarbeet (Beta vulgaris) somatic cell selections. Weed Sci., v. 46, n. 1, p. 13-23, 1998.
WRIGHT, T. R.; PENNER, D. In vitro and whole-plant magnitude and cross-resistance characterization of two imidazolinone-resistant sugarbeet (Beta vulgaris) somatic cell selections. Weed Sci., v. 46, n. 1, p. 24-29, 1998a.

WRIGHT, T. R.; PENNER, D. Cell selection and inheritance of imidazolinone resistance in sugarbeet (Beta vulgaris). Theoret. Appl. Genetics, v. 49, n. 5, p. 612-620, 1998b.

WRIGHT, T. R.; PENNER, D. Corn (Zea mays) acetolactate synthase sensitivity to four classes of ALSinhibiting herbicides. Weed Sci., v. 46, n. 1, p. 8-12, 1998 c. 